\title{
PSYCHOSOCIAL HELPING PROCESSES IN A HETEROGENEOUS SAMPLE OF SELF-HELP GROUPS
}

\author{
RICHARD W. WOLLERT \\ University of Saskatchewan
}

\begin{abstract}
To adequately conceptualize the potential that self-help groups hold for delivering human services it is important to know about the helping exchanges between members. Only a few quantified comparative studies of this issue have been completed, and the extent of their generalizability is not known. This paper reports a replication of one of these studies. Rating patterns on a group process questionnaire for the thirteen groups participating in this replication study were robustly correlated with those for the eight groups in the original study. The results also suggested that patterns of helping activities are affected by such organizational factors as meeting format and level of professional involvement. To clarify the nature of these mediating factors and their impact on group functioning it will be useful to explicate the dimensions of heterogeneity between groups in the future and to further refine existing techniques for the measurement of helping exchanges.
\end{abstract}

Self-help groups are a source of adjustive assistance for a great many persons with a wide variety of problems in living. The scope and size of these groups have understandably led numerous political figures and government administrators to express an interest in drawing upon the potential they hold for the delivery of mental health and other human services (Carter, 1975; Hall, 1980; Romeder, 1982; Task Force on Mental Health Services in Saskatchewan, 1983). Adequate conceptualization of this potential requires a clear understanding, however, of the psychosocial helping processes that occur within self-help groups and of how these processes are related to personal change. Unfortunately, while numerous reports have been published about self-help processes (see Dean, 1970; Katz, 1970; Barish, 1971; Bumbalo \& Young, 1973; Caplan, 1974; Dumont, 1974; Hurvitz, 1974; Antze, 1976; Back \& Taylor, 1976; Katz \& Bender, 1976; Killilea,

Portions of this paper were presented at the annual meeting of the Canadian Psychological Association in 1984. This study was supported by U.S. National Institute of Mental Health Grant R01 MH33716. The author thanks his research team of Nancy Barron, Linda Dixon, Lucy Eakins, Kathy Tuma, John Wadsworth, and Steven Andrews for their many contributions. The support of the Regional Research insitute for Human Services at Portland State University is also gratefully acknowledged. Reprint requests should be sent to Richard Wollert, Department of Psychology, University of Saskatchewan, Saskatoon, Saskatchewan, Canada S7N 0w0. 
1976; Levy, 1976; Lieberman \& Bond, 1976; Gartner \& Riessman, 1977; Evans, 1979), no consensus exists on those of greatest importance. For example, the most frequently cited helping processes include role modeling, social reinforcement and rewards, support and comfort, and advice and guidance. Less frequently cited processes include acceptance,' self-disclosure, punishment, imparting knowledge, and sharing daily events. Least frequently mentioned as characteristic processes are normalization via social comparison, confrontation, discrimination training, offering feedback, providing alternative conceptual frameworks, instilling hope, and validation of self-worth.

Obviously, it is unlikely that all these processes occur so often and with such impact that they should be considered fundamental to the self-help approach. An evaluation and reconciliation of the various published reports would thus be very welcome in bringing conceptual order to this area. Several obstacles make it difficult, however, to achieve this integration. One major problem is that almost all process analyses have been based on naturalistic observations of self-help groups, and process constructs have rarely been clearly defined and operationalized. Where group processes have been operationalized, only one self-help group or a single type of self-help group has often been studied (see Lieberman \& Bond, 1976). This single case approach provides little or no information about those processes that recur across groups and those that are specific to certain types of self-help groups. Still a third problem is that processes which are deemphasized or even avoided have been insufficiently studied. This limits the scope of a process analysis of self-help groups and increases the difficulty of comparing them with other important personal change groups.

These observations suggest that comparative studies of clearly defined and operationalized self-help processes could make some valuable contributions toward extending our knowledge of self-help interventions. Such studies would also be useful in delineating the potential that self-help groups hold for the delivery of mental health services to specific target populations, and for elaborating the range of techniques that may be effective in facilitating personal change.

Several years ago Leon Levy and I developed the Helping Processes Questionnaire (HPQ), an instrument for assessing the perceived frequency of 28 helpgiving activities, and administered it to members of seven different self-help groups in the State of Indiana (Levy, 1979; Wollert, Levy, \& Knight, 1982). We found that these groups emphasized a variety of supportive, insight-oriented, and expressive processes. We also found that they avoided confrontive processes and complicated techniques that are often practiced by professionals. Overall, we concluded that self-help groups provide their members with a broad range of therapeutic exchanges but do this by drawing on safe and simple techniques that are grounded in everyday experience,

Although these results quantified a variety of helping processes, some observations suggested the generalizability of our findings might be robust whereas others suggested it might be limited. Supporting the first view was the fact that our data were obtained from several different groups. In addition, a subsequent study by Leo Levy (1981) showed that members of a British self-help organization for schizophrenics and their families gave similar HPQ responses to those given 
by our subjects. Supporting the second view was the possibility that the HPQ was administered to a highly selected sample of self-help groups. Only two types of mental health-oriented groups were included in our original sample (Wollert et al., 1982), and all of the groups were similar in that they (a) emphasized problemcentered discussions between members during meetings; (b) did not, with the exception of one group, include professional facilitators; (c) were organized under national auspices; and (d) were directed in all respects by their members. While this approach was justified by the lack of quantified data then available about self-help processes, it should also be recognized that self-help groups are very heterogeneous on these and other dimensions. It could thus be argued that our sample was representative of only a narrow cross-section of the set of self-help groups operating in a single geographical region.

As ptart of a subsequent three-year project sponsored by the United States National Institute of Mental Health, my research team administered the HPQ to members of 13 self-help groups drawn from a broad cross-section of groups operating in the Portland, Oregon community. Several of these groups were professionally facilitated, some deemphasized problem-centered discussions in favour of social activities and lectures, and others were organized under a local rather than a national auspice. The Oregon sample was thus, quite heterogeneous compared to the Indiana sample. This heterogeneity was ideal for testing the generalizability of our previous findings as well as determining the relative significance of various helping processes for types of self-help groups beyond the scope of our original work.

This paper presents some of the results of this survey and discusses their implications for these issues.

\section{METHODS}

\section{Groups}

The full name and composition of each surveyed group are included in Table 1. These 13 groups were selected from a comprehensive inventory of Portland self-help groups that was compiled to support the activities of a self-help clearinghouse operated by the research team (Wollert \& Barron, 1983; Wollert, Tuma, Wadsworth, \& Barron, in press). One hundred and thirty-six different groups composed of 19,000 members were included in this inventory when the survey was designed. Seventy-five percent of the groups dealt with stressful life transitions of health and mental health issues, 16 percent focused on personal growth, and three percent dealt with violence. We roughly maintained this distribution in our sample. In addition to being representative, we wanted our sample to reflect different organizational models. We therefore purposely included groups that served different adjustive functions for their members, and that varied with respect to control, interaction, naturalism, and auspice. These "categories of heterogeneity" are described at the bottom of Table 1. We did, however, restrict our survey to those groups that met at least twice a month.

\section{Questionnaire}

The HPQ assesses 27 help-giving activities that are commonly described in the literature on psychotherapy techniques, or that we identified through ob- 


\section{TABLE 1}

\section{Descriptive Information About Self-Help Groups that Completed the HPQ}

Study

Group Name

Indiana Study

Alcoholics Anonymous

Overeaters Anonymous

Parents Anonymous

Take Off Pounds

Sensibly (TOPS) No, 1

TOPS No. 2

Emotions Anonymous

Make Today Count

Parents Without

Partners (PWP)

Oregon Study

Alcoholics Anonymous

Anorexic Aid

Dignity, Inc.

Gay Women

Newcomers

Parents United

PWP

Retired Associates

Recovery, Inc.

Stress Control

Stroke Club

WeightRight

Women's Group

\section{Composition}

Other

Comparisonst $N^{2}$

\author{
alcoholics \\ overweight persons \\ abusive parents \\ overweight persons \\ overweight persons \\ dysphoric persons \\ cancer patients \\ single parents
}

B C E M G S R O I N A

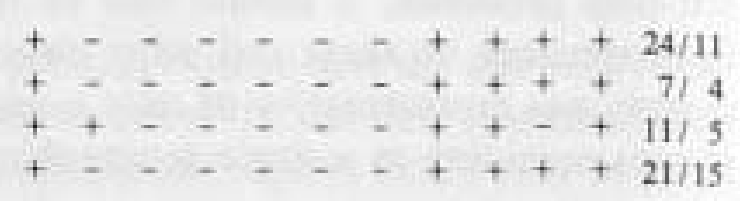

$+\ldots+\ldots+++19 / 13$

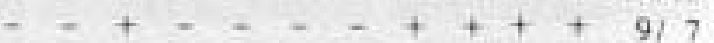

$-+\ldots+\ldots+++\ldots+1216$

$-+\cdots++\ldots+++16 / 11$

1. The presence $(+)$ or absence $(-)$ of 11 qualities, denoted by the following abbreviations, has been coded for each group:

$\mathrm{B}=$ the group is used to control problematic overt behaviour;

C = the group is used to cope with specific stressful life events, conditions, or transitions;

$\mathrm{E}=$ the group is used to deal with recurring emotional or cognitive reactions of a general nature;

$\mathrm{M}=$ the group is used to maintain a lifestyle that is not supported by the prevailing culture or is socially ostracized;

$\mathrm{G}=$ the group is used to pursue growth and self-actualization;

$\mathrm{S}=$ the group is used to obtain access to social activities;

$\mathrm{R}=$ the group is used to obtain needed material resources or services;

$\mathrm{O}=$ members make most critical decisions without external consultation;

1 = members interact directly with one another during group meetings, and engage in personally-focused discussions:

$\mathrm{N}=$ naturalistic helping techniques predominate in that mental health professionals do not function as counselors within the group:

$\mathrm{A}=$ organizational auspices reside outside as well as within the group (e.g., at a national level).

2. The first number in this category indicates mean attendance at meetings and the second indicates how many questionnaires were collected.

3. Several recently inactive members also completed questionnaires. 
TABLE 2

\section{Summary Definitions of Items on the HPQ}

\section{Process Name}

Empathizing

Mutual affirmation

Instilling hope

Checking in,

Explanation

Normalization

Positive reinforcement

Self-disclosure

Encouraging catharsis

Instilling confidence

Bchavioural prescription

Encouragement of sharing

Justification

Functional analysis

Personal goal setting

Reflection

Discrimination

Consensual validation

Offering feedback

\section{Summary Definition}

When a person expresses his emotions in the group, other members let that person know that they understand and share his feelings.

Members assure one another that they are worthwhile and valuable people.

Group members assure other members that their problems will be worked out positively.

Group members share everyday experiences, thoughts, or feelings with other members.

Members provide explanations which help other group members to better understand themselves or their reaction to a situation.

When a person describes his actions or emotions as strange or abnormal, other group members assure him that his behaviour is normal.

The group applauds or rewards desirable behaviour.

Group members disclose to other members, experiences, fantasies, thoughts, or emotions which are personal and which they would not normally tell others.

The group encourages the release of emotions.

Members assure one another that they are capable of handling their problems.

Group members suggest things another member might do to overcome a problem.

When a member brings up a problem, other members ask for additional information about it, but do so in nonthreatening ways.

Members let other members know they were justified in feeling or acting as they did in response to some situation.

Members try to understand a problem by breaking it down and determining such things as what went on before the problem arose, how the person reacted, and what happened afterwards.

Members set personal goals and check their progress toward achieving them.

In order to clarify how a group member thinks or feels about something, other members rephrase in so many words what they believe the person has said.

When a member describes a presently happening situation as similar to past situations, other members point out how these situations differ.

Members use the group to determine if their personal view of the world is accurate.

Members disclose their feelings and impressions about one another in face to face interactions. 
Modeling

Behavioural proseription

Confrontation

Normative reference

Extinction

Behavioural rehearsal

Requesting feedback

Punishment
Members explain how they would handle a problem brought up by another member, and demonstrate how they would react if they were faced with this person's problem.

Group members identify actions they believe another member should not take.

Group members challenge one another to explain themselves or account for their behaviour.

The group has rules as to how members should feel, think, and act. Members refer to these rules.

The group ignores undesirable behaviour.

Group members suggest how another member might act to handle a problem, and then ask the person to practice this behaviour in front of the group.

A group member asks other group members how he impresses them, and how they feel about him.

The group criticizes or punishes members for undesirable behaviour.

serving many different self-help groups (Levy, 1979). Each activity is described in ordinary language, and as it might be manifested and recognized within a selfhelp group context. Summary definitions of the items in the HPQ are presented in Table 2, although the questionnaire itself does not include the names associated with the various definitions. Responsents rate each activity on a five point scale, with 1 defined as "an inaccurate description" of what happens in the group and how often it happens, and 5 defined as "a very accurate description."

The version of the HPQ used in the present study was embedded within a questionnaire of 48 similarly-formatted items called the Group Process Questionnaire (GPQ). We have decided to discuss the HPQ here rather than the GPQ because of its articulation with our previous work. One item from our original questionnaire, called "group goal-setting," was not included in the scale administered in this study because it focused on an organizational issue whereas the other items asked about more personal issues.

\section{Procedures}

Thirteen of the 14 groups asked to participate in the study agreed to do so. We believe this high participation rate reflects the credibility our project achieved within the community by providing consultive and informational services through our clearinghouse to self-help groups and community residents at the same time that we were pursuing a research mission. Questionnaires were distributed only after positive working relationships were established with the members of the various groups. Generally, this took place after two team members had attended about five group meetings as nonparticipant observers. Although our observer pairs did not take notes during meetings, they did consult each other after meetings and constructed post-meeting narratives according to guidelines that were developed for this purpose.

In most of the groups, a group member distributed and collected the questionnaires. We asked all members of groups with 13 or fewer participants to com- 
plete the HPQ. In four larger groups we asked the group as a whole to (a) pick 12 potential respondents from among those who would most accurately represent their group and to (b) give our questionnaires to them. Our estimated return rate of questionnaires, based on the average attendance at meetings and on the number of questionnaires returned by peer nominees, averaged 86 percent per group and ranged from 62 to 100 percent. Table 1 presents the return rate data for both this and the earlier study.

\section{RESULTS}

\section{Heterogeneity}

Table I presents a sign summary of the similarities and differences between groups over several important comparative categories. The presence or absence of each key feature was determined from group narratives, published materials, and questionnaires about the groups that were part of our self-help inventory. Therefore, although the reliability of this classification system has not been determined, the assignments 1 have made are based on substantial documentation. Adopting the mean percent of disagreement in signs between pairs of groups as an index of heterogeneity, it is clear that the set of groups in the second study is much more heterogeneous than the set in the first study $(40 \% \mathrm{vs}, 20 \%$, respectively).

\section{Overall Rating Patterns on the Helping Processes Questionnaire}

Table 3 presents the means of the mean group ratings on the items of the $H P Q$. The average item rating was very close to the midpoint of the scale for groups in each study, and no difference between studies was found on this measure $(t(19)=.81, p, .25)$. Considerable variation in the means of the individual items was apparent, however, as they ranged from about 1.5 to 4.1 . Within both studies, high ratings were given for supportive (e.g., item numbers 1 , $2,3,6)$, expressive $(4,8,9)$, and insight-oriented $(5,14)$ activities. Low ratings were reported for complex interventions used by professionals $(20,25)$, punitive interactions $(24,27)$, and threatening exchanges that have been associated with the context of group psychotherapy $(19,22,26)$. A very strong correlation between item means indicated that rating patterns in the second study were highly similar to those in the first study $(r=.87, p(.001)$.

$T$-tests were applied to each set of item means to explore rating variations between the studies. Groups in the second study gave lower ratings than groups in the first study for two behavioural processes $(15,21)$ and two normative processes $(18,23)$. They gave higher ratings for two of the activities that I have referred to as interpersonally threatening $(19,22)$.

\section{Intercorrelations Among Self-Help Groups}

Tables 4 and 5 present the correlations between HPQ ratings over all items for each pair of groups participating in the two studies. Strong correlations were found among all groups but the Retired Associates in the second study. Our narrative descriptions also noted that this was the only group for which some members questioned the appropriateness of classifying the group as a self-help 


\section{TABLE 3}

Means of the Mean Ratings of Self-Help Groups on the HPQ in Two Studies

\begin{tabular}{|c|c|c|c|}
\hline Process & $\begin{array}{c}\text { Combined } \\
\text { Studies } \\
(N=21)\end{array}$ & $\begin{array}{l}\text { Indiana } \\
\text { Study } \\
(N=8)\end{array}$ & $\begin{array}{c}\text { Oregon } \\
\text { Study } \\
(N=13)\end{array}$ \\
\hline 1. Empathizing & 4.08 & 4.17 & 4.02 \\
\hline 2. Mutual affirmation & 4.03 & 3.87 & 4.141 \\
\hline 3. Instilling hope & 3.76 & 3.87 & 3.70 \\
\hline 4. Checking in & 3.70 & 3,71 & 3.70 \\
\hline 5. Explanation & 3.66 & 3.82 & 3.56 \\
\hline 6. Normalization & 3.56 & 3.40 & 3.661 \\
\hline 7. Positive reinforcement & 3.53 & 3.80 & 3.36 \\
\hline 8. Self-disclosure & 3.39 & 3,46 & 3,35 \\
\hline 9. Encouraging catharsis & 3.38 & 3.49 & 3.32 \\
\hline 10. Instilling confidence & 3.37 & 3.39 & 3.36 \\
\hline 11. Behavioural prescription & 3.30 & 3.43 & 3.23 \\
\hline 12. Requesting elaboration & 3.27 & 3.48 & 3.14 \\
\hline 13. Justification & 3.24 & 3.25 & 3.24 \\
\hline 14. Functional analysis & 3.12 & 3.28 & 3.02 \\
\hline 15. Personal goal setting & 3.05 & 3.66 & $2.66^{\circ}$ \\
\hline 16. Reflection & 2.96 & 3.10 & 2.88 \\
\hline 17. Discrimination & 2.92 & 3.28 & 2.70 \\
\hline 18. Consensual validation & 2.61 & 2.90 & 2.43 \\
\hline 19. Offering feedback & 2.48 & 2.00 & $2.78^{*}$ \\
\hline 20. Modeling & 2.45 & 2.29 & 2.54 \\
\hline 21. Behavioural proscription & 2.36 & 2.69 & $2.16^{\circ}$ \\
\hline 22. Confrontation & 2.14 & 1.67 & $2.43^{*}$ \\
\hline 23. Normative reference & 2.01 & 2.51 & $1.70^{\circ}$ \\
\hline 24. Extinction & 1.99 & 2.21 & 1,86 \\
\hline 25. Behavioural rehearsal & 1.89 & 1.76 & 1.98 \\
\hline 26. Requesting feedback & 1.73 & 1.72 & 1.74 \\
\hline 27. Punishment & 1.63 & 1.79 & 1.53 \\
\hline Average item rating & 2.95 & 3.04 & $2.90^{2}$ \\
\hline
\end{tabular}

Note: All t-tests were two-tailed.

1. The means for these items are 4.31 and 3.83 for the Oregon groups, if the Retired Associates group is excluded, and both are different from the Indiana group means at the , 05 significance level.

2. The average item ratings are 3.00 and 2.98 for the combined data and the Oregon groups, respectively, if Retired Associates data are excluded.

\footnotetext{
$\bullet p<.05$.

$\because p<.01$.

$\cdots p$. 001 .
}

group. A reanalysis of the item means without the data from the Retired Associates group replicated the differences obtained in the original set of $t$-tests. It also indicated that the other Oregon groups gave higher ratings than the Indiana groups for two supportive processes $(2,6)$. 
TABLE 4

Correlations Among Self-Help Groups in the Indiana Study for HPQ Ratings Over All Items

$\begin{array}{lccccccc}\text { Groups } & \text { T1 } & \text { T2 } & \text { PA } & \text { OA } & \text { PWP } & \text { EA } & \text { MTC } \\ \text { AA } & .69 & .76 & .63 & .70 & .78 & .80 & .66 \\ \text { T1 } & & .86 & .50 & .71 & .61 & .57 & .56 \\ \text { T2 } & & & .42 & .70 & .56 & .50 & .48 \\ \text { PA } & & & & .78 & .73 & .61 & .77 \\ \text { OA } & & & & & .68 & .72 & .81 \\ \text { PWP } & & & & & & .88 & .65 \\ \text { MTC } & & & & & & & .70\end{array}$

Note: Allicorrelations are significant at the .05 level, applying a two-tailed test.

1. The following abbreviations are used to stand for the participating groups: $\mathrm{AA}=\mathrm{Alco}-$ holics Anonymous, $\mathrm{T} 1$ and $\mathrm{T} 2=$ Tops No. 1 and No, 2, PA $=$ Parents Anonymous, $\mathrm{OA}=$ Overeaters Anonymous, $\mathrm{PWP}=$ Parents Without Partners, EA $=$ Emotions Anonymous, $\mathrm{MTC}=$ Make Today Count.

\section{TABLE 5}

Correlations Among Self-Help Groups in the Oregon Study for HPQ Ratings Over All Items

Groups

$\begin{array}{lcccccccccccc} & \text { SC } & \text { RCV } & \text { GAY } & \text { SKE } & \text { AA } & \text { WMN } & \text { ANR } & \text { DI } & \text { PU } & \text { RA } & \text { WR } & \text { NEW } \\ \text { PWP } & .78 & .87 & .75 & .77 & .79 & .62 & .61 & .71 & .72 & .25 & .51 & .59 \\ \text { SC } & & .75 & .83 & .69 & .76 & .83 & .81 & .81 & .90 & .18 & .82 & .66 \\ \text { RCV } & & & .66 & .72 & .77 & .58 & .61 & .69 & .63 & .36 & .57 & .66 \\ \text { GAY } & & & .65 & .71 & .88 & .75 & .80 & .92 & .14 & .68 & .61 \\ \text { SKE } & & & & .70 & .49 & .57 & .64 & .65 & .37 & .48 & .56 \\ \text { AA } & & & & & .71 & .65 & .76 & .74 & .30^{\prime} & .74 & .72 \\ \text { WMN } & & & & & & .74 & .79 & .83 & .15 & .76 & .61 \\ \text { ANR } & & & & & & & .66 & .80 & .13 & .75 & .64 \\ \text { DI } & & & & & & & & .77 & .25 & .65 & .76 \\ \text { PU } & & & & & & & & & .07 & .79 & .56 \\ \text { RA } & & & & & & & & & & .28 & .37 \\ \text { WR } & & & & & & & & & & & .68\end{array}$

Note: All correlations are significant at the .05 level, applying a two-tailed test, except for those denoted by a (') symbol.

1. The following abbreviations are used to stand for the participating groups: PWP = Parents Without Partners; $\mathrm{SC}=$ Stress Control; RCV = Recovery, Inc,; GAY = Gay Women; SKE = Stroke Club; AA = Alcoholics Anonymous; WMN = Women's Group; $\mathrm{ANR}=$ Anorexic Aid; $\mathrm{DI}=$ Dignity, Inc, $\mathrm{PU}=$ Parents United; RA $=$ Retired Associates; WR $=$ WeightRight; NEW $=$ Newcomers.

\section{Rating Patterns Among Different Types of Self-Help Groups}

Our descriptive materials, correlational data, and observations suggested initially that the Oregon sample could be broken down into four types of groups: 
(a) peer-facilitated discussions of personal issues (Alcoholics Anonymous, Gay Women, Parents Without Partners, Recovery, Inc., Stroke Club, WeightRight, Women's Group); (b) professionally-facilitated discussions of personal issues (Anorexic Aid, Parents United, Streș Control); (c) social interactions among peers (Dignity, Inc, Newcomers); and (d) lectures on topics of general, as opposed to personal, interest (Retired Associates). Table 6 presents the means for the HPQ items reported by these types of groups. Considering groups as the unit of analysis rather than members, the number of observations that have thus far been collected limit the application of inferential statistical tests. Descriptively, the data nonetheless suggest several interesting differences between groups. The lecture format type of group is set apart from all other group types, for example, by the limited range of psychosocial helping activities that it fosters. Social interaction groups, in contrast, provide opportunities for members to provide moderate amounts of support to one another, as reflected in the high ratings for items $1,2,3$, and 10 . The pattern of high scores for nonthreatening disclosure (4) and low scores for threatening disclosure (8) indicate, however, that this approach is less intense than the personally-focused approach. While the personallyfocused groups held similar orientations toward the resolution of personal concerns, the item means of the professionally-facilitated groups were greater than those of the peer-facilitated groups for all but two helping activities commonly associated with professional practice $(5,7,8,9,11,12,14,15,16,17,19,20,21$, $22,25,26$ ).

This pattern of ratings suggested that group interactions become less naturalistic as professional involvement in self-help groups is increased. Rating patterns for two items $(8,17)$ were inconsistent with this conclusion, however, and relatively modest differences were obtained for several others (e.g., 11, 16, 19), raising the possibility that pooling the data for the peer-facilitated groups may have obscured the impact that professional involvement has on the activities of self-help groups. To further explore this issue, the peer-facilitated groups that followed an unstructured format and contained many helping professionals (Gay Women, WeightRight, Women's Group) were differentiated from structured groups that contained relatively few professionals (Alcoholics Anonymous, Parents Without Partners, Stroke Club, Recovery, Inc.). The rating pattern of the first set of groups, which were considered to have high levels of professional involvement, was similar to that reported for the professionally-led groups, In contrast, large rating differences were apparent between the second set of groups and those that were professionally-facilitated. These contrasting patterns are presented in Table 6.

\section{DISCUSSION}

In this paper, I have presented a study which examined the psychosocial helping activities occurring within self-help groups. The pattern of interventions we identified in earlier research with a narrow cross-section of groups was found in this subsequent research with a broad cross-section of groups. Our previous findings are generalizable at a very robust level, and point to the conclusion that self-help groups draw upon a common core of interventions in attempting to meet the needs of their members. These interventions mobilize mutual support and en- 


\section{TABLE 6}

\section{Mean HPQ Ratings by Different Classes of Self-Help Groups in the Oregon Sample}

Breakdown of all groups by activities and facilitators

\begin{tabular}{|c|c|c|c|c|c|c|}
\hline Process & $\begin{array}{l}\text { LGI } \\
(N=1)\end{array}$ & $\begin{array}{c}\text { SI } \\
(N=2)\end{array}$ & $\begin{array}{c}\text { PE } \\
(N=7)\end{array}$ & $\begin{array}{c}\text { PL } \\
(N=3)\end{array}$ & $\begin{array}{c}\text { HPI } \\
(N=3)\end{array}$ & $\begin{array}{c}\text { LPI } \\
(N=4)\end{array}$ \\
\hline 1. Empathizing & 2.0 & 3.5 & 4.4 & 4.3 & 4.6 & 4.4 \\
\hline 2. Mutual affirmation & 2.0 & 4.1 & 4.4 & 4.4 & 4.7 & 4.1 \\
\hline 3. Instilling hope & 2,1 & 3.5 & 4.0 & 3.7 & 3.7 & 4.2 \\
\hline 4. Checking in & 2.4 & 3.9 & 3.8 & 3.7 & 4.6 & 3.2 \\
\hline 5. Explanation ${ }^{2}$ & 2.1 & 3.0 & 3.8 & 4.0 & 4.0 & 3.6 \\
\hline 6. Normalization & 1.6 & 3.4 & 3.9 & 4,0 & 3.8 & 4.0 \\
\hline 7. Positive reinforcement ${ }^{2}$ & 2.9 & 3.4 & 3.3 & 3.8 & 3.8 & 2.9 \\
\hline 8. Self-disclosure & 1.8 & 2.6 & 3.7 & 3.6 & 4.1 & 3.3 \\
\hline 9. Encouraging catharsis 2 & 1.3 & 3.2 & 3.4 & 3.9 & 4.3 & 2.8 \\
\hline 10. Instilling confidence & 2,1 & 3.5 & 3.6 & 3.2 & 4.0 & 3.3 \\
\hline \multicolumn{7}{|l|}{ 11. Behavioural } \\
\hline \multicolumn{7}{|l|}{ 12. Requesting } \\
\hline claboration ${ }^{2}$ & 1.6 & 3.1 & 3.2 & 3.7 & 4.1 & 2.5 \\
\hline 13. Justification & 1.6 & 2.9 & 3.4 & 3.2 & 4.0 & 3.0 \\
\hline 14. Functional analysis 2 & 2.0 & 2.6 & 3.1 & 3.5 & 4.1 & 2.4 \\
\hline 15. Personal goal setting 2 & 1.4 & 2.8 & 2.7 & 2.9 & 2.9 & 2.6 \\
\hline 16. Reflection ${ }^{2}$ & 1.7 & 3.0 & 2.9 & 3.2 & 3.5 & 2.4 \\
\hline 17. Discrimination 2 & 1.7 & 2.8 & 2.9 & 2.8 & 3.2 & 2.7 \\
\hline 18. Consensual validation & 2.0 & 2.6 & 2.3 & 2.8 & 2.2 & 2.4 \\
\hline 19. Offering feedback 2 & 2.0 & 2.4 & 2.8 & 3.2 & 3.5 & 2.3 \\
\hline 20. Modeling 2 & 1.5 & 2.4 & 2.6 & 3.0 & 2,9 & 2.3 \\
\hline \multicolumn{7}{|l|}{ 21. Behavioural } \\
\hline proscription ${ }^{2}$ & 1.6 & 1.9 & 2.2 & 2.6 & 2.3 & 2.0 \\
\hline 22. Confrontation ${ }^{2}$ & 1.8 & 2.4 & 2.3 & 3.0 & 3.4 & 1.5 \\
\hline 23. Normative reference & 2.1 & 1.9 & 1.6 & 1.8 & 1.3 & 1.8 \\
\hline 24. Extinction & 2,4 & 2.4 & 1.8 & 1.5 & 1.4 & 2.1 \\
\hline 25. Behavioural rehearsal ${ }^{2}$ & 1.2 & 2.0 & 1.7 & 2.9 & 2.0 & 1.4 \\
\hline 26. Requesting feedback ${ }^{2}$ & 1.1 & 2,3 & 1.5 & 2.1 & 1.8 & 1.3 \\
\hline 27. Punishment & 1.8 & 1.6 & 1.5 & 1.5 & 1.5 & 1.4 \\
\hline
\end{tabular}

1. Abbreviations stand for the following classes of groups: LGI = lectures of general interest; $\mathrm{SI}=$ social interactions; $\mathrm{PE}=$ peer-facilitated personal discussions; $\mathrm{PL}=$ professionally facilitated personal discussions; HPI = unstructured meeting format, high percentage of members were helping professionals; LPI = structured meeting format, low percentage of members were helping professionals.

2. Processes associated with professional practices.

courage personal expression and the achievement of insight. Their simplicity and positively-toned qualities suggest they are grounded in the everyday interpersonal experiences of members, and may thus be considered "naturalistic." 
Although the present research underscores many similarities between selfhelp groups, it also points to differences that were not captured by the scope of our original reports. In that work, we found behavioural techniques were used more frequently by groups organized around the goal of enhancing behavioural control, than by groups directed toward coping with stressful life events (Wollert, Levy, \& Knight, 1982). In the present study we found that a set of Oregon selfhelp groups reported lower ratings than a set of Indiana groups for behavioural and normative processes, and higher ratings for supportive and interpersonally threatening processes. These differences presumably reflect the relatively nonbehavioural focus of the Oregon groups, and their greater emphases on personal growth and professional involvement. The HPQ data for the Oregon groups also indicated that the inclusion of professionals in self-help groups increases the likelihood that professionalized helping activities, many of which are relatively complicated and threatening in tone, will occur at group meetings.

This last finding is important because it provides quantitative evidence supporting our previous anecdotal observation (Wollert, Levy, \& Knight, 1980) that human service professionals tend to practice their professions within a self-help setting. It also implies that professional roles in self-help groups should be structured so they are consistent with group goals. A significant facilitative role, for example, might be reserved for professionals in a group oriented toward personal growth and what Yalom (1975) has referred to as "interpersonal learning." Alternatively, groups that emphasize peer support and the preservation of their autonomy might severely restrict the activities of professionals at their meetings.

Differences in the structure and composition of self-help groups therefore apparently lead to different patterns of helping activities between groups. Proceeding from this assumption, I believe that it will be important to further specify and dimensionalize organizational variables in future studies of self-help groups. Such observations could eventually provide a basis for the derivation of group typologies that would be of an empirically-grounded nature, in contrast to the rationally-grounded typologies that have thus far been formulated by self-help researchers (Killilea, 1976). It would also be valuable to administer outcome measures in conjunction with process measures during the course of future research, and to factor analyze the resultant data set.

Bringing these suggested lines of research together, it will be possible to outline more precisely than ever before the interrelationships between organizational variables, helping processes, and personal change in self-help groups. This, in turn, will enable us to formulate realistic and effective policies for achieving an integration of self-help groups and the formal human services delivery system.

\section{RÉSUMÉ}

Pour conceptualiser adéquatement le potentiel des groupes d'entraide a titre de ressources sociales, il importe de savoir comment se font les échanges mutuels entre les membres. On ne trouve que quelques études quantitatives et comparatives dans ce domaine et il reste a savoir jusqu'où on peut les généraliser. Le présent article est une reprise de l'une de ces études. Quand, dans un questionnaire portant sur les processus de groupe, on fait apprécier les patterns, il existe une forte corrélation entre les participants des treize 
groupes de la nouvelle étude et ceux des huit groupes de l'étude originale. Les résultats suggèrent de plus que les patterns relatifs aux activités d'aide sont influencés par des facteurs organisationnels comme la forme des rencontres et le niveau d'implication profeśsionnelle. Pour clarifier la nature de ces facteurs de médiation et leur effet sur le fonctionnement du groupe, il serait utile d'expliquer les dimensions d'hétérogénéité entre les groupes et de raffiner les techniques de mesures des échanges mutuels.

\section{REFERENCES}

Antze, P. (1976). The role of ideologies in peer psychotherapy organizations: Some theoretical considerations and three case studies. Journal of Applied Behavioral Science, 12, 232-346.

Back, K.W., \& Taylor, R.C. (1976). Self-help groups: Tool or symbol, Journal of Applied Behavioral Science, 12, 295-309.

Barish, H. (1971). Self-help groups. In Encyclopedia of social work (Vol. 2, 16th ed.). New York: National Association of Social Workers, Inc., 1163-1169.

Bumbalo, J.A., \& Young, D.E. (1973). The self-help phenomenon. American Journal of Nursing, 73, 1588-1591.

Caplan, G. (1974). Support systems and community mental health. New York: Behavioral Publications.

Carter, N. (1975). Volunteers: The untapped potential. Ottawa: Canadian Council on Social Development.

Dean, S. (1970), Self-help psychotherapy: Mental patients rediscover will-power. International Journal of Social Psychiatry, 17, 72-78.

Dumont, M. (1974). Self-help treatment programs. American Journal of Psychiatry, 131, 631-635.

Evans, G. (1974). The Family Circle guide to self-help. New York: Ballantine Books.

Gartner, A., \& Riessman, F. (1977). Self-help in the human services. San Francisco: JosseyBass.

Hall, E. (1980). Canada's national-provincial health program for the 1980s: A commitment for renewal. Ottawa: Health and Welfare Canada.

Hurvitz, N. (1974). Peer self-help psychotherapy groups: Psychotherapy without psychotherapists. In P.M. Roman \& H.M. Trice (Eds.), The sociology of psychotherapy (pp. 84-138). New York: Jason Aronson.

Katz, A.H. (1970). Self-help organizations and volunteer participation in social welfare. Social Work, 15, 51-60.

Katz, A.H., \& Bender, E.I. (1976). The strength in us. New York: New Viewpoints.

Killilea, M. (1976). Mutual help organizations: Interpretations in the literature, In G. Caplan \& M. Killilea (Eds.), Support systems and mutual help (pp. 37-93). New York: Grune \& Stratton.

Levy, L. (1981). The National Schizophrenia Fellowship: A British self-help group. Social Psychiatry, 16, 129-135.

Levy, L.H. (1976). Self-help groups: Types and psychological processes. Journal of Applied Behavioral Science, 12, 310-322.

Levy, L.H. (1979). Processes and activities in groups. In M.A. Lieberman \& L.D. Borman (Eds.), Self-help groups for coping with crisis (pp. 234-271). San Francisco: JosseyBass.

Lieberman, M.A., \& Bond, G.R. (1976). The problem of being a woman: A survey of 1700 women in consciousness-raising groups. Journal of Applied Behavioral Science, 12. 363-390.

Romeder, J.M. (1982). Self-help groups in Canada. Ottawa: Health and Welfare Canada.

Task Force on Mental Health Services in Saskatchewan. (1983). The forgotten constitu- 
ents. Saskatoon, Saskatchewan: Saskatchewan Mental Health Association.

Wollert, R.W., \& Barron, N.B. (1983). Avenues of collaboration. In D.L. Pancoast, P. Parker, \& C. Froland (Eds.), Rediscovering self-help: Its role in social care (pp. 105-123). Beverly Hills, California: Sage.

Wollert, R.W., Levy, L.H., \& Knight, B. (1980). Make Today Count: A collaborative model for professionals and self-help groups. Professional Psychology, II, 130-138.

Wollert, R.W., Levy, L.H., \& Knight, B.G. (1982). Help-giving in behavioral control and stress coping self-help groups. Small Group Behavior, 13, 204-218.

Wollert, R.W.. Tuma, C., Wadsworth, J., \& Barron, N.B. (in press). An information and referral model for improving community utilization of self-help groups. Information and Referral.

Yalom, 1.D. (1975). The theory and practice of group psychotherapy. New York: Basic Books. 